\title{
Comparison of in vitro activity of five antifungal agents against dermatophytes, using the agar dilution and broth microdilution methods
}

\author{
Comparação da atividade in vitro de cinco agentes antifúngicos para \\ dermatófitos, usando os métodos de diluição em \\ ágar e microdiluição em caldo
}

\author{
Crystiane Rodrigues Araújo Mota ${ }^{1}$, Karla Carvalho Miranda ${ }^{1}$, Janine de Aquino Lemos ${ }^{1}$, \\ Carolina Rodrigues Costa ${ }^{1}$, Lúcia Kioko Hasimoto e Souza ${ }^{1}$, Xisto Sena Passos ${ }^{1}$, \\ Hildene Meneses e Silva ${ }^{1}$ and Maria do Rosário Rodrigues Silva ${ }^{1}$
}

\begin{abstract}
The purpose of this study was to compare the agar dilution and broth microdilution methods for determining the minimum inhibitory concentration (MIC) of fluconazole, itraconazole, ketoconazole, griseofulvin and terbinafine for 60 dermatophyte samples belonging to the species Trichophyton rubrum, Trichophyton mentagrophytes and Microsporum canis. The percentage agreement between the two methods, for all the isolates with $\leq$ 2 dilutions that were tested was $91.6 \%$ for ketoconazole and griseofulvin, $88.3 \%$ for itraconazole, $81.6 \%$ for terbinafine and $73.3 \%$ for fluconazole. One hundred percent agreement was obtained for Trichophyton mentagrophytes isolates evaluated with ketoconazole and griseofulvin. Thus, until a reference method for testing the in vitro susceptibility of dermatophytes is standardized, the similarity of the results between the two methods means that the agar dilution method may be useful for susceptibility testing on these filamentous fungi.
\end{abstract}

Key-words: In vitro susceptibility. Agar dilution. Broth microdilution. Dermatophytes.

\section{RESUMO}

0 propósito do presente trabalho foi comparar os métodos de diluição em ágar e diluição em caldo para a determinação de concentração inibitória mínima de fluconazol, itraconazol, cetoconazol, griseofulvina e terbinafina para 60 amostras de dermatófitos pertencentes às espécies, Trichophyton rubrum, Trichophyton. mentagrophytes e Microsporum canis. A porcentagem de acordo entre os dois métodos para todos os isolados testados considerando-se valores $\leq 2$ diluições, foram de 91,6\% para cetoconazol e para griseofulvina, de 88,3\% para itraconazol, de 81,6\% para terbinafina e de 73,3\% para fluconazol. Uma concordância de 100\% foi obtido para isolados de Trichophyton mentagrophytes avaliados com cetoconazol e griseofulvina. Desta forma, até que um método de referência seja padronizado para testar a suscetibilidade in vitro para os dermatófitos, os resultados semelhantes encontrados para os dois métodos fazem com que o método de diluição em ágar possa ser útil no teste de suscetibilidade para estes fungos filamentosos.

Palavras-chaves: Suscetibilidade in vitro. Diluição em ágar. Microdiluição em caldo. Dermatófitos.

Infections caused by dermatophytes are probably the most common cutaneous fungal diseases in humans and animals 4 . Increasing numbers of antifungal agents have been used for treating dermatophytosis ${ }^{2}$. However, not all species have the same susceptibility patterns, and relative or absolute microbial resistance may occur in relation to some dermatophytes ${ }^{6}$. Research to evaluate in vitro susceptibility has been hampered

1. Tropical Pathology and Public Health Institute, Federal University of Goiás, Goiânia, GO, Brazil.

Address to: Dra. Maria do Rosario Rodrigues Silva. Rua 15, 108/700, Setor Oeste, 74140-090 Goiânia, G0, Brazil.

Telefax: $55623521-1839$

e-mail: rosario@iptsp.ufg.br

Received in 10/10/2008

Accepted in 15/05/2009 by the lack of reliable in vitro techniques for determining the minimum inhibitory concentration (MIC) of antifungal agents against dermatophytes.

Various methods, such as broth macro and microdilutions, agar dilution, Etest ${ }^{\circledast}$, Sensititre ${ }^{\circledast}$ colorimetric microdilution panels and disk diffusion have been used for determining the susceptibility of dermatophytes to antifungal agents ${ }^{72} 1314151619$. However, there is no reference method available for filamentous fungi. Dermatophytes were not included in the M38-A document, published by the Clinical and Laboratory Standards Institute in $2002^{5}$, in which MICs for several antifungal agents against conidium-forming filamentous fungi are determined.

Standardization and the development of new methods for determining the in vitro susceptibility of dermatophytes to the antifungal activities of different drugs are needed. In order to 
compare such results, we used the agar dilution and broth microdilution methods for five antifungal agents against 60 dermatophyte strains belonging to three different species.

\section{MATERIAL AND METHODS}

Isolates. A total of 60 dermatophyte strains, including Trichophyton rubrum (27), Trichophyton mentagrophytes (14) and Microsporum canis (19) were tested. All of the microorganisms were collected from skin lesions and nails, from patients at the University Hospital of Goiania, Brazil, between March and July 2006. The fungi were maintained in sterile distilled water at room temperature and, prior to testing, the strains were subcultured onto potato dextrose agar (PDA) medium at $28^{\circ} \mathrm{C}$ for seven days, to ensure the viability and purity of the inoculum. Candida parapsilosis ATCC 22019 was included as a reference strain.

Antifungal agent dilutions. The drugs were obtained from their respective manufacturers: fluconazole (Pfizer International, New York, NY, USA), ketoconazole and itraconazole (Jansen Pharmaceuticals, Beerse, Belgium), terbinafine (Novartis Research Institute, Vienna, Austria) and griseofulvin (Sigma Chemical Company, St. Louis, MO, USA). Fluconazole was dissolved in distilled water, while the other drugs were dissolved in $100 \%$ dimethyl sulfoxide (Sigma-Aldrich). All of the drugs were then prepared as stock solutions and serial twofold dilutions were performed. The final concentrations ranged from 0.125 to $64 \mu \mathrm{g} / \mathrm{ml}$ for fluconazole, 0.03 to $16 \mu \mathrm{g} / \mathrm{ml}$ for ketoconazole, itraconazole and terbinafine, and 0.03 to $8 \mu \mathrm{g} / \mathrm{ml}$ for griseofulvin.

Broth microdilution method. The broth microdilution assay for antifungal susceptibility testing on dermatophytes was performed in accordance with the Clinical and Laboratory Standards Institute guidelines in the M38-A document on filamentous fungi' ${ }^{\text {, with some }}$ modifications. The inoculum suspensions of dermatophytes were prepared from seven-day cultures grown on potato dextrose agar at $28^{\circ} \mathrm{C}$. The fungal colonies were covered with approximately 10 $\mathrm{ml}$ of distilled water, and the suspensions were made by scraping the surface with the tip of a sterile loop. The resulting mixture of conidia and hyphal fragments was removed and transferred to sterile tubes. Heavy particles in the suspension were allowed to settle for 15 to 20 minutes at room temperature. The optical density of the suspensions containing conidia and hyphal fragments was read at 530nm and adjusted to transmittance of 65 to $70 \%$. The concentration of colony-forming units (CFU/ml) was quantified by plating $10 \mathrm{ml}$ of suspension in Sabouraud dextrose agar. The plates were incubated at $28^{\circ} \mathrm{C}$ and the colonies were counted when the growth became visible. Each suspension was diluted (1:50) with RPMI 1640 medium (Sigma Chemical Co, St. Louis, MO, USA) to obtain the final inoculum concentration of 0.4 to $5 \times 10^{4}$ cells $/ \mathrm{ml}$. Aliquots of $100 \mu \mathrm{l}$ of these suspensions were inoculated into microtiter plate wells containing $100 \mu \mathrm{l}$ of specific antifungal drug concentrations. The microdilution plates were incubated at $28^{\circ} \mathrm{C}$ and readings were made every $24 \mathrm{~h}$ until growth in the drug-free control well was shown. Each assay was carried out in duplicate.
Endpoint criteria. For azole agents and griseofulvin, the MIC was defined as the lowest concentration that produced prominent inhibition of growth (approximately 80\% inhibition), while for terbinafine, it was defined as the lowest concentration showing $100 \%$ growth inhibition ${ }^{18}$.

Agar dilution method. The agar dilution method was performed as described by Souza et $\mathrm{al}^{20}$, with slight modification. The antifungal agents were serially two-fold diluted in RPMI 1640 agar broth medium, to obtain concentrations ranging from 1.25 to $640 \mu \mathrm{g} / \mathrm{ml}$ for fluconazole, 0.3 to $160 \mu \mathrm{g} / \mathrm{ml}$ for ketoconazole, itraconazole and terbinafine, and 0.3 to $80 \mu \mathrm{g} / \mathrm{ml}$ for griseofulvin. These antifungal agents were diluted 1:10 in plates containing melted RPMI agar medium. Steel perforators were inserted into these plates after the medium had solidified, in order to produce 37 holes of $3 \mathrm{~mm}$ diameter, as shown in Figure 1. The holes were filled with $10 \mu \mathrm{l}$ of inoculum containing 0.4 to $5 \times 10^{4}$ cells $/ \mathrm{ml}$

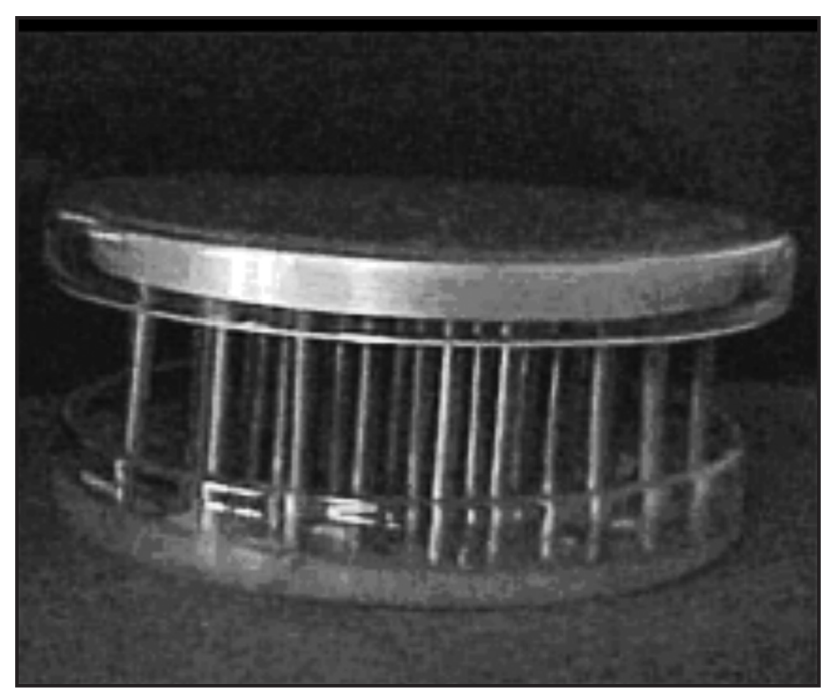

FIGURE 1

Formation of holes of $3 \mathrm{~mm}$ in diameter in melted RPMI agar medium by using steel perforators, in the agar dilution method.

(as described for the broth microdilution method). The plates were incubated at $28^{\circ} \mathrm{C}$ and the growth was read every $24 \mathrm{~h}$, until growth in the drug-free control hole was shown. For all the antifungal agents tested, the MIC was read as the lowest drug concentration that prevented any discernible growth.

Quality control. One CLSI quality control strain (Candida parapsilosis ATCC 22019), which was incubated at $28^{\circ} \mathrm{C}$ for $48 \mathrm{~h}$ was included on each day of testing in order to check the accuracy of drug dilutions (fluconazole, ketoconazole and itraconazole) and the reproducibility of the results.

Data analysis. All tests were performed in duplicate. $\mathrm{MIC}_{50}$ and $\mathrm{MIC}_{90}$, at which respectively $50 \%$ and $90 \%$ of the isolates were inhibited, along with MIC ranges, were determined to facilitate comparisons between drug activity levels (Table 1). For each isolate, the two methods were considered to be in agreement if the difference in MIC was no more than two dilutions, as described in Table 2. 
TABLE 1

In vitro antifungal susceptibility of 60 strains of dermatophytes as determined by broth dilution and agar dilution.

\begin{tabular}{|c|c|c|c|c|c|c|c|}
\hline \multirow[b]{2}{*}{ Species } & \multirow[b]{2}{*}{ Drugs } & \multicolumn{3}{|c|}{ Broth dilution $(\mu \mathrm{g} / \mathrm{ml})$} & \multicolumn{3}{|c|}{ Agar dilution $(\mu \mathrm{g} / \mathrm{ml})$} \\
\hline & & range & $\mathrm{MIC}_{\text {g0 }}$ & $\mathrm{MIC}_{9}$ & range & $\mathrm{MIC}_{\text {g }}$ & $\mathrm{MIC}_{\mathrm{p}}$ \\
\hline \multirow[t]{5}{*}{ Trichophyton. rubrum $(\mathrm{n}=27)$} & Fluconazole & $2-32$ & 8 & 32 & $1-64$ & 8 & 64 \\
\hline & Itraconazole & $0.03-4$ & 0.125 & 0.5 & $0.03-4$ & 0.06 & 0.25 \\
\hline & Ketoconazole & $0.03-4$ & 0.125 & 4 & $0.03-8$ & 0.125 & 1 \\
\hline & Terbinafine & $0.03-0.5$ & 0.125 & 0.25 & $0.03-0.5$ & 0.03 & 0.125 \\
\hline & Griseofulvin & $0.25-2$ & 0.5 & 1 & $0.06-4$ & 0.5 & 1 \\
\hline \multirow[t]{5}{*}{ Trichophyton mentagrophytes $(\mathrm{n}=14)$} & Fluconazole & $4-16$ & 16 & 16 & $2-64$ & 8 & 64 \\
\hline & Itraconazole & $0.03-0.25$ & 0.125 & 0.25 & $0.03-0.125$ & 0.06 & 0.125 \\
\hline & Ketoconazole & $0.03-1$ & 0.125 & 0.25 & $0.06-4$ & 0.5 & 1 \\
\hline & Terbinafine & $0.03-0.5$ & 0.06 & 0.25 & $0.03-0.06$ & 0.03 & 0.03 \\
\hline & Griseofulvin & $0.25-1$ & 0.5 & 0.5 & $0.25-1$ & 0.5 & 1 \\
\hline \multirow[t]{5}{*}{ Microsporum Canis $(\mathrm{n}=19)$} & Fluconazole & $2-32$ & 8 & 16 & $2-64$ & 8 & 64 \\
\hline & Itraconazole & $0.03-0.25$ & 0.125 & 0.25 & $0.03-4$ & 0.125 & 0.5 \\
\hline & Ketoconazole & $0.03-4$ & 0.125 & 0.25 & $0.125-8$ & 0.25 & 1 \\
\hline & Terbinafine & $0.03-1$ & 0.125 & 0.25 & $0.03-1$ & 0.03 & 0.03 \\
\hline & Griseofulvin & $0.06-8$ & 0.25 & 0.5 & $0.06-8$ & 0.25 & 1 \\
\hline \multirow[t]{5}{*}{ Over all $(n=60)$} & Fluconazole & $2-32$ & 8 & 32 & $1-64$ & 16 & 64 \\
\hline & Itraconazole & $0.03-4$ & 0.125 & 0.25 & $0.03-4$ & 0.06 & 0.25 \\
\hline & Ketoconazole & $0.03-4$ & 0.125 & 1 & $0.03-8$ & 0.25 & 1 \\
\hline & Terbinafine & $0.03-1$ & 0.125 & 0.25 & $0.03-1$ & 0.03 & 0.125 \\
\hline & Griseofulvin & $0.06-8$ & 0.5 & 1 & $0.06-8$ & 0.5 & 1 \\
\hline
\end{tabular}

MIC: minimal inhibitory concentration, $\mu \mathrm{g} / \mathrm{ml}$ : micrograma/milliliter.

TABLE 2

Agreement between minimal inhibition concentrations (MICs) of five antifungal agents for Trichophyton rubrum $(\mathrm{n}=27)$, Trichophyton mentagrophytes $(\mathrm{n}=14$ ) and Microsporum canis $(\mathrm{n}=19)$ obtained using the broth microdilution and agar dilution methods.

Number of isolates with differences in MICs, from the broth microdilution and

\begin{tabular}{|c|c|c|c|c|c|c|c|c|c|}
\hline \multirow[b]{2}{*}{ Species } & \multirow[b]{2}{*}{ Antifungals } & \multicolumn{7}{|c|}{ agar dilution methods, within the following dilutions* } & \multirow{2}{*}{$\begin{array}{l}\text { Percentage } \\
\text { agreement** }^{* *}\end{array}$} \\
\hline & & $<-2$ & -2 & -1 & 0 & +1 & +2 & $>+2$ & \\
\hline \multirow[t]{5}{*}{ Trichophyton rubrum } & Fluconazole & 3 & 1 & 7 & 1 & 6 & 6 & 3 & 77.7 \\
\hline & Itraconazole & 2 & 6 & 5 & 1 & 9 & 3 & 1 & 88.8 \\
\hline & Ketoconazole & 4 & 0 & 1 & 5 & 12 & 5 & 0 & 85.2 \\
\hline & Terbinafine & 3 & 12 & 8 & 3 & 0 & 0 & 1 & 85.2 \\
\hline & Griseofulvin & 3 & 6 & 5 & 7 & 6 & 0 & 0 & 88.8 \\
\hline \multirow[t]{5}{*}{ Trichophyton mentagrophytes } & Fluconazole & 3 & 1 & 2 & 1 & 3 & 1 & 3 & 57.1 \\
\hline & Itraconazole & 2 & 1 & 5 & 2 & 0 & 4 & 0 & 85.7 \\
\hline & Ketoconazole & 0 & 0 & 0 & 1 & 4 & 9 & 0 & 100 \\
\hline & Terbinafine & 3 & 2 & 5 & 4 & 0 & 0 & 0 & 78.5 \\
\hline & Griseofulvin & 0 & 0 & 3 & 3 & 6 & 2 & 0 & 100 \\
\hline \multirow[t]{5}{*}{ Microsporum canis } & Fluconazole & 0 & 2 & 3 & 3 & 5 & 2 & 4 & 78.9 \\
\hline & Itraconazole & 1 & 1 & 2 & 2 & 8 & 4 & 1 & 89.5 \\
\hline & Ketoconazole & 0 & 1 & 0 & 2 & 4 & 11 & 1 & 94.7 \\
\hline & Terbinafine & 3 & 5 & 5 & 4 & 1 & 0 & 1 & 78.9 \\
\hline & Griseofulvin & 1 & 0 & 3 & 10 & 3 & 1 & 1 & 89.5 \\
\hline \multirow[t]{5}{*}{ Overall } & Fluconazole & 6 & 4 & 12 & 5 & 14 & 9 & 10 & 73.3 \\
\hline & Itraconazole & 5 & 8 & 12 & 5 & 17 & 11 & 2 & 88.3 \\
\hline & Ketoconazole & 4 & 1 & 1 & 8 & 20 & 25 & 1 & 91.6 \\
\hline & Terbinafine & 9 & 19 & 18 & 11 & 1 & 0 & 2 & 81.6 \\
\hline & Griseofulvin & 4 & 6 & 11 & 19 & 16 & 3 & 1 & 91.6 \\
\hline
\end{tabular}

*The differences in dilutions between the two methods were determined by taking the broth microdilution method as the reference. ***agreement between the two methods for each isolate was taken to be no difference in MIC of more than two dilutions. 


\section{RESULTS}

The isolates tested produced detectable growth over the period between 72 and $120 \mathrm{~h}$ of incubation through both the broth microdilution and the agar dilution method. MICs were determined by means of the broth microdilution method after four days of incubation, for all the isolates of Trichophyton mentagrophytes, and after five days for Trichophyton rubrum and Microsporum canis isolates. By using agar dilution, detectable growth was observed after five days of incubation for all the isolates (Figure 2).

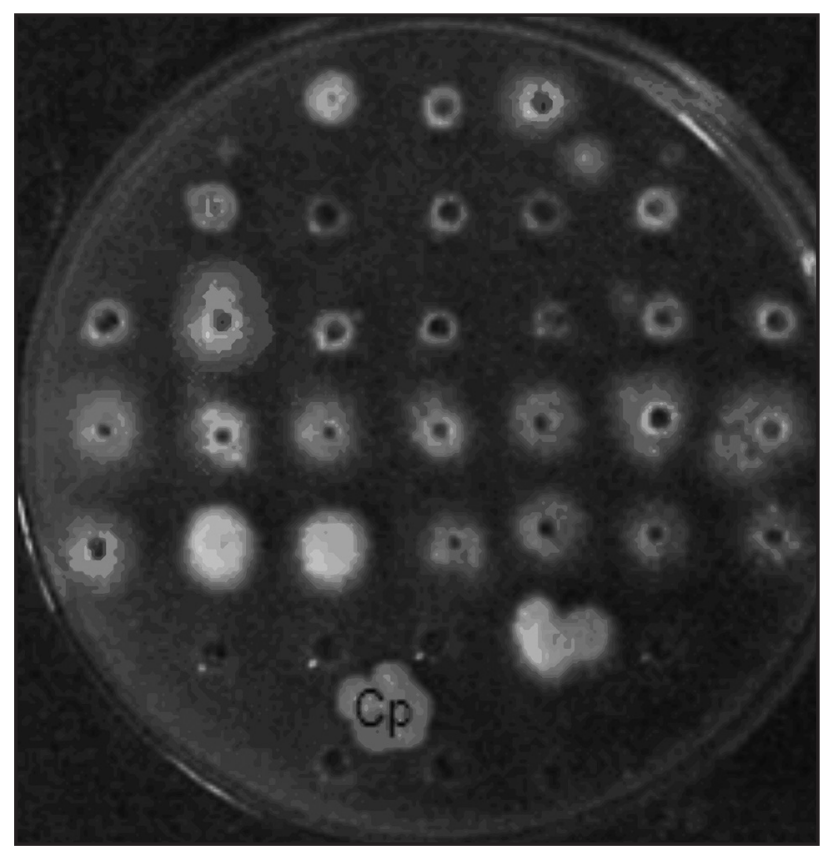

FIGURE 2

Detectable growth of dermatophyte isolates (fluconazole $\mathrm{MIC}=2 \mu \mathrm{g} / \mathrm{ml}$ ), from the agar dilution method, after five days of incubation at $28^{\circ} \mathrm{C}$. Cp: Candida parapsilosis ATCC 22019

Table 1 shows the MIC ranges, $\mathrm{MIC}_{50}$ and $\mathrm{MIC}_{90}$ that were determined using the microdilution and agar dilution methods. In general, the ranges between these values were very narrow.

The percentage agreement between the two methods, taken such there were no differences in MICs greater than two dilutions, is summarized in Table 2. The highest levels of agreement were noted with ketoconazole (91.6\%) and griseofulvin (91.6\%), for all the isolates tested. Excellent agreement (100\%) was obtained with ketoconazole and griseofulvin for Trichophyton mentagrophytes isolates. The lowest concordance was observed for fluconazole. The agreement rate was $73.3 \%$ for all dermatophytes, while it was only $57.1 \%$ for Trichophyton mentagrophytes. Fluconazole MIC values were higher using the agar dilution method than using the broth microdilution method.

Using the broth microdilution method, the MICs shown by fluconazole, ketoconazole and itraconazole in relation to Candida parapsilosis (ATCC 22019) were within the established ranges. The agar dilution method showed MICs for this strain that were slightly higher than those shown by broth microdilution (taking the limit of no more than two dilutions).

\section{DISCUSSION}

Although the Clinical and Laboratory Standards Institute has published a document regarding tests for filamentous fungi ${ }^{5}$, no reference method has been established for testing the drug susceptibility of dermatophytes. Some parameters like temperature, incubation time and endpoint are difficult to standardize for in vitro susceptibility testing relating to filamentous fungi ${ }^{11}$.

Despite the incubation temperature of $35^{\circ} \mathrm{C}$ that was established by the Clinical and Laboratory Standards Institute in relation to filamentous fungi, we performed the incubation at $28^{\circ} \mathrm{C}$. In a preliminary experiment carried out in our laboratory, the dermatophyte strains presented better growth at $28^{\circ} \mathrm{C}$ than at $35^{\circ} \mathrm{C}$ (data not shown). According to Pujol et al ${ }^{16}$, MICs are more reproducible at $28^{\circ} \mathrm{C}$ and the dermatophyte growth is more characteristic.

The MIC endpoints for our study were determined after five days for the agar dilution and after four to five days for the broth microdilution. The readings of MIC values for each method that were made every day made it possible to define this incubation time. Our results are similar to those of Ghannoun et $\mathrm{al}^{10}$, who incubated dermatophytes for four days by using the broth microdilution method.

In the present study, similar results were obtained for MIC ranges, $\mathrm{MIC}_{50}$ and $\mathrm{MIC}_{90}$ for fluconazole, itraconazole, ketoconazole, terbinafine and griseofulvin in relation to 60 isolates of dermatophytes, investigated using both the agar dilution and the broth dilution method. The comparison between the two methods performed by Yoshida et $\mathrm{a}^{21}$ presented similar MICs for fluconazole, amphotericin $\mathrm{B}$ and flucytosine, in relation to yeast isolates.

For all the isolates, we observed more than $73 \%$ concordance between the results by using these two methods for determining MICs for dermatophyte strains tested with fluconazole, ketoconazole, itraconazole, terbinafine and griseofulvin. It is interesting to note that the agreement between the two methods varied according to the dermatophyte species and the drug tested. For Trichophyton mentagrophytes, the agreement was 57.1\% with fluconazole and $100 \%$ with ketoconazole and griseofulvin (Table 2).

As shown in Table 2, the greatest disagreement found in this study was in relation to fluconazole. Fernández-Torres et al ${ }^{8}$ also found poor agreement for fluconazole, between the methods of broth microdilution and Etest (a method based on diffusion of the antifungal agent into an agar medium). However, there are no reasons for these disagreements between pairs of methods that have been found with fluconazole. A greater number of strains may be needed to explain these results.

Confirming the validity of our results, we found that the MIC ranges for dermatophytes in relation to different drugs were similar to those previously found by several researchers using the broth microdilution method ${ }^{679} 1617$. Although high MIC values were found for some dermatophytes in our results, it was not possible to determine whether the isolates were susceptible or 
resistant to the antifungal agents because no breakpoints have yet been established. Until a reference method for testing the antifungal susceptibilities of dermatophytes has been standardized, we can merely suggest that the broth microdilution and agar dilution methods may be useful for testing the susceptibility of these fungi.

\section{REFERENCES}

1. Alió AB, Mendoza SM, Zambrano EA, Díaz E, Cavallera E. Dermatophytes growth curve and in vitro susceptibility test: a broth micro-titration method. Medical Mycology 43: 319-325, 2005.

2. Barchiesi F, Arzeni D, Camiletti V, Simonetti O, Cellini A, Offidani A, Scalise G. In vitro activity of posaconazole against clinical isolates of dermatophytes. Journal of Clinical Microbiology 39: 4208-4209, 2001.

3. Chadeganipor M, Nilipour S, Havaei A. In vitro evalution of griseofulvin against clinical isolates of dermatophytes from Isfahan. Mycoses 47: 503-507, 2004.

4. Chinelli PAV, Sofiatti AA, Nunes RS, Martins JEC. Dermatophyte agents in the city of São Paulo, from 1992 to 2002. Revista do Instituto de Medicina Tropical de São Paulo 45: 259-263, 2003

5. Clinical and Laboratory Standards Institute. Reference Method for Broth Dilution Antifungal Susceptibility Testing of Filamentous Fungi; Approved Standard. CLSI document M38-A 2002.

6. Fernández-Torres B, Cabañes FJ, Carrillo-Munõz AJ, Esteban A, Inza I, Abarca L, Guarro J. Collaborative evaluation of optimal antifungal susceptibility testing condition for dermatophytes. Journal of Clinical Microbiology 40: 3999-4003, 2002.

7. Fernández-Torres B, Carrillo AJ, Martín E, Del Palacio A, Moore MK, Valverde A, Serrano M, Guarro J. In vitro activities of 10 antifungal drugs against 508 dermatophyte strains. Antimicrobial Agents and Chemotherapy 45: 2524-2528, 2001.

8. Fernández-Torres B, Carrillo-Muñoz A, Ortopeda M, Pujol I, Pastor FJ, Guarro J. Interlaboratory evaluation of the Etest ${ }^{\circledR}$ for antifungal susceptibility testing of dermatophytes. Medical Mycology 41: 125-130, 2003.

9. Ghannoum MA, Arthington-Skaggs B, Chaturvedi V, Espinel-Ingroff A, Pfaller MA, Rennie R, Rinaldi MG, Walsh TJ. Interlaboratory study of quality control isolates for a broth microdilution method (modified CLSI M38-A) for testing susceptilities of dermatophytes to antifungals. Journal of Clinical Microbiology 44: 4353-4356, 2006.
10. Ghannoum MA, Chaturvedi V, Espinel-Ingroff A, Pfaller MA, Rinaldi MG, Lee-Yang W, Warnock W. Intra and interlaboratory study of a method for testing the antifungal susceptilities of dermatophytes. Journal of Clinical Microbiology 42: 2977-2979, 2004. 11.

11. Jessup CJ, Warner J, Isham N, Hasan I, Ghannoum A. Antifungal susceptibility testing of dermatophytes: establishing a medium for inducing conidial growth and evaluation of susceptibility of clinical isolates. Journal of Clinical Microbiology 38: 341-344, 2000.

12. Karaca N, Koç A. In vitro susceptibility testing of dermatophytes: comparison of disk diffusion and reference broth dilution methods. Diagnostic Microbiology and Infectious Disease 48: 259-264, 2004.

13. Niewerth M, Splanemann V, Korting HC, Ring J, Abeck D. Antimicrobial susceptibility testing of dermatophytes-comparison of the agar macrodilution and broth microdilution tests. Chemotherapy 44: 31-35,1998.

14. Perea S, Fothergill AW, Sutton DA, Rinaldi MG. Comparison of in vitro activities of voriconazole and five established antifungal agents against different species of dermatophytes using a broth macrodilution method. Journal of Clinical Microbiology 39: 385-388, 2001.

15. Perrins N, Howell SA, Moore M, Bond R. Inhibition of the growth in vitro of Trichophyton mentagrophytes, Trichophyton erinacei and Microsporum persicolor by miconazole and chlorhexidine. Veterinary Dermatology 16: 330$333,2005$.

16. Pujol I, Capilla J, Fernández-Torres B, Ortopeda M, Guarro J. Use of the sensititre colorimetric microdilution panel for antifungal susceptibility testing of dermatophytes. Journal of Clinical Microbiology 40: 2618-2621, 2002.

17. Santos DA, Hamdan JS. Evaluation of broth microdilution antifungal susceptibility testing conditions for Trichophyton rubrum. Journal of Clinical Microbiology 43: 1917-1920, 2005

18. Santos JJ, Barros MES, Hamdan JS. Establishing a method of inoculum preparation for susceptibility testing of Trichophyton rubrum and Trichophyton mentagrophytes. Journal of Clinical Microbiology 44: 98-101, 2006.

19. Santos JJ, Paula CR, Viani FC, Gambale W Susceptibility testing of Trichophyton rubrum and Microsporum canis to three azoles by E-test. Journal de Mycologie Medicale 11: 42-43, 2001.

20. Souza LKH, Oliveira CMA, Ferri PH, Santos SC, Oliveira Júnior JG, Miranda ATB Lião LM, Silva MRR. Antifungal properties of brazilian cerrado plants. Brazilian Journal of Microbiology 33: 247-249, 2002

21. Yoshida T, Jono K, Okonogi K. Modified agar dilution susceptibility testing method for determining in vitro activities of antifungal agents, including azole compounds. Antimicrobial Agents and Chemotherapy 41:1349-1351, 1997. 